\title{
Avaliação educacional em larga escala: performatividade e perversão da experiência educacional
}

Large-scale educational assessments: performativity and perversion of educational experience

\author{
Jarbas Dametto* \\ Universidade de Passo Fundo \\ Rosimar Serena Siqueira Esquinsani** \\ Universidade de Passo Fundo
}

Resumo $\mathrm{O}$ texto propõe um debate crítico sobre as avaliações educacionais em larga escala e suas implicações junto à experiência pedagógica cotidiana. Por meio de revisão teórica e de uma compilação de estudos recentes sobre o tema, analisa-se a questão, concebendo a avaliação externa padronizada como um instrumento cujos meios e resultados alimentam ideais performáticos, tomando-se a performance como um princípio de legitimação típico da atualidade, perpassado pela concorrência e pela perspectiva produtivista extraída do âmbito privado. Debatem-se também subprodutos das avaliações, como a emergência dos rankings educacionais, da responsabilização docente, a apropriação midiática dos resultados e as possíveis implicações de tais fenômenos. Por fim, exploram-se alguns dos efeitos da quantificação e da classificação voltada à educação, apontando prejuízos que um olhar baseado na performatividade pode acarretar à prática educacional.

PALAVRAS-CHAVE: Avaliação educacional; Performatividade; Práticas pedagógicas.

\begin{abstract}
This text proposes a critical debate about large-scale educational assessments and their implications by the pedagogical experience everyday. Through theoretical review and a compilation of recent studies on the topic, it analyses the issue, conceiving the assessment standardized external as an instrument whose means and results feed ideal performer, taking the performance as a principle of typical today, the present paper legitimacy by competition and productionist perspective extracted from private. It is debated also about some evaluation sub products, such as the emergence of educational accountability rankings, teachers' responsibility, media ownership of results and the implications of such phenomena. Finally, it is explored some of the effects of quantification and classification geared to education pointing losses that a look based on performativity can lead to educational practice.
\end{abstract}

KEYWORDS: Educational assessment; Performativity; Pedagogical practices. 


\section{Introdução}

As avaliações educacionais externas empreendidas na atualidade constituem um processo cuja ação extrapola a mera constatação das condições da educação ofertada em uma dada instituição ou rede de ensino em um recorte delimitado de tempo. Embora tais levantamentos e exames pareçam incidir sobre dados vinculados ao passado - ao que já foi aprendido ou ensinado, ao que a instituição escolar já alcançou frente ao currículo proposto, ao que o aluno "reteve em sua memória" ou evoluiu até então evidencia-se que sua maior potência atrela-se ao prognóstico e à prescrição, e não ao diagnóstico ou à constatação, ou seja, é na determinação do futuro da prática educacional que ela assenta sua pertinência enquanto mecanismo político.

É inevitável percebermos que tais procedimentos, com olhares voltados ao já realizado, desenham a ordem futura da coisa avaliada. Os relatórios finais de uma avaliação, bem como os próprios procedimentos desta, implícita ou explicitamente, conformam as ações políticas sobre a realidade da qual se ocupam. Dentro desta perspectiva, tomam-se as avaliações, acima de tudo, como ferramentas de poder, capazes de coagir, de modo ostensivo ou velado, os sujeitos envolvidos no processo educacional e, em consequência, traçar o destino do trabalho realizado nas instituições as quais eles pertencem.

As avaliações educacionais em larga escala possuem um viés performático de organização e interpretação de seus dados, sendo a redução de toda uma realidade complexa a um índice numérico, a expressão máxima desta opção. Embora a formação de rankings não seja assumida como objetivo último dessas avaliações, as comparações inevitavelmente ocorrem, estabelecendo um estado explícito ou implícito de concorrência e algumas de suas posturas peculiares, como, por exemplo, o uso de subterfúgios para a conquista de um melhor posicionamento nas tabelas comparativas, bem como a desistência frente a uma atestada, e então inegável, inferioridade.

Partindo das proposições acima, pretende-se, neste escrito, problematizar a avaliação externa em larga escala, em suas práticas e na forma de divulgação e tratamento dos resultados, buscando lançar algumas hipóteses acerca do modo como esse fenômeno contemporâneo age na construção de critérios valorativos sobre a ação educativa, e, consequentemente, nos rumos das práticas pedagógicas empreendidas cotidianamente nas escolas. Para tal, se lança mão de um referencial pós-estruturalista de análise e de uma breve compilação de trabalhos recentemente publicados que buscam dar conta das imbricações existentes entre as avaliações acima referidas, a cultura da performatividade e a construção de um novo ethos educacional, enredado em princípios que podem perverter os reais motivos pelos quais se constrói a prática educativa.

\section{Performance e performatividade}

Performance é um conceito que porta vários significados, contemplando áreas e ideias distintas. Dentre as concepções que se vinculam ao termo performance, podemos relacionar a sua inscrição no campo da arte, que contempla uma potente e inquietante forma de expressão artística híbrida, que se posiciona nas fronteiras entre o 
teatro, a dança, o ritual, as artes visuais, a experiência e a intervenção, em um processo criativo que, por vezes, convida o expectador a participar de seu enquadre. Neste contexto, o artista ganha o atributo de performer, sujeito que faz de si mesmo elemento de sua expressão artística. O termo também se situa dentro do pensamento antropológico e sociológico, ao descrever a dimensão dos atos nas interações sociais, o "como fazem", e não somente os motivos pelos quais o fazem, análise que pode debruçar-se sobre os corpos e sobre a linguagem, tomando esta última como um fenômeno de realização, e não apenas de representação. Por fim, pode-se conceber a performance como um meio de regulação, uma forma de apresentação de desempenhos que fomenta a performatividade, que seria um modo um tanto ilusório de desenvolver um juízo de valor acerca das práticas e das instituições submetidas a avaliações padronizadas (ICLE, 2010).

É dentro da última perspectiva mencionada que se situa a presente análise: a performance e a performatividade como um conjunto de fenômenos relacionados ao posicionamento de cada elemento em um entorno social, vinculado ao que se faz visível e comparável de uma experiência ou realidade e ao que disso se traduz em discurso. Grosso modo, abordar-se-á a performatividade que se configura como um fenômeno da ordem do poder, na qual o desempenho de indivíduos e instituições é posto à luz através de técnicas específicas que os enredam política e discursivamente, incitando movimentos de adesão ou resistência nos sujeitos envolvidos.

Tal leitura acerca da performatividade foi proposta primeiramente por Lyotard, momento no qual o autor, nos fins da década de 1970, propõe que os critérios de legitimação do conhecimento e da ação nas sociedades pós-industriais passaram a ser pautados pela relação entre a entrada e a saída em um sistema, o melhor desempenho/ produtividade entre o input e output, aquilo que alimenta o sistema e aquilo que o sistema devolve em termos de resultados (LYOTARD, 2000; BALL, 2010). A performance, assim compreendida,

[...] implica julgamento, comparação e exposição, tomados respectivamente como formas de controle, de atrito e de mudança. Performances - de sujeitos individuais ou organizações - servem como medidas de produtividade ou resultados, como formas de apresentação da qualidade ou momentos de promoção ou inspeção. Elas significam, encapsulando ou representando um valor, a qualidade ou a valia de um indivíduo ou de uma organização dentro de um campo de julgamento. (BALL, 2010, p. 38).

A necessária mensuração acerca do desempenho, que alimenta o princípio de legitimação nas sociedades pós-industriais e que vem sendo acolhido fervorosamente também por países em desenvolvimento, se vê formalizada nas avaliações e inspeções padronizadas voltadas à educação em massa. Criar indicadores, métodos de avaliação, relatórios periódicos, bem como "melhorar" os índices de qualidade a cada nova coleta de informações, têm sido empreendimentos para os quais governos estão dedicando especial atenção e volumosos investimentos financeiros. À semelhança da empresa privada, o setor público passou a buscar visibilidade e legitimidade através do marketing, sendo este fundamentado em índices de eficácia e eficiência, bem como por meio de demonstrativos numéricos de progresso e crescimento. 
[...] a performatividade funciona para empurrar as instituições do setor público à maior convergência com o setor privado. Paradoxalmente, a performatividade requer das instituições do setor público tanta atenção às mudanças simbólicas e às manipulações quanto ela exige das mudanças reais. Ela encoraja as instituições a se preocuparem cada vez mais com seu estilo, sua imagem, sua semiótica, com a maneira como apresentam as coisas mais do que como as fazem funcionar. De fato, o projeto de transparência por meio da performatividade produz maior complexidade e opacidade, uma vez que as organizações do setor público gastam tempo, dinheiro e energia com gestão das aparências, marketing e promoção. (BALL, 2004, p. 1117-1118).

Nota-se, nas últimas décadas, o deslocamento das funções do Estado: ele se distancia da condição de provedor de serviços e garantidor de cidadania, como pensado no Estado de bem-estar social, para a posição de um Estado avaliador, cujos meios "[...] são justificados e legitimados como uma importante maneira de tornar transparente para o público a forma como as instituições atuam e utilizam os recursos públicos" (SANTOS, 2004, p. 1151-1152). Deste modo, uma superficial, arbitrária e coercitiva "prestação de contas" (accountability) acaba por se revestir de dignos ideais, conquistando o aval de diversos setores da sociedade.

A origem das avaliações em larga escala remete a configuração do Estado avaliador e a toda a série de pressupostos teórico-ideológicos e instrumentos de atuação que vieram em seu bojo. O Estado avaliador pode ser conceituado como o Estado que adota "[...] um ethos competitivo, neodarwinista, passando a admitir a lógica do mercado, através da importação para o domínio público de modelos de gestão privada, com ênfase nos resultados ou produtos dos sistemas educativos" (AFONSO, 2009, p. 49).

Partindo desta perspectiva, o Estado avaliador legitima o controle social sobre o trabalho docente (aferição de resultados). Este Estado é regulamentado pela produtividade, legitimando-se através de práticas pretensamente transparentes, em que o emprego do dinheiro público é traduzido em serviços educacionais com resultados mensuráveis, o que traduz-se na chamada "cultura do desempenho" (SANTOS, 2004, p. 1151). No contexto do Estado avaliador, “[...] a fé em indicadores mensuráveis passa a ser o exemplo paradigmático das mudanças neoliberais e neoconservadoras" (AFONSO, 2009, p. 50).

Com base nesta lógica, solidifica-se a avaliação de sistema, que "[...] referese à aferição padronizada do rendimento escolar dos alunos, realizada no âmbito do sistema nacional ou dos sistemas estaduais de avaliação do ensino básico" (BARRETTO et. al, 2001, p. 51), também conhecida como avaliação em larga escala.

A avaliação de larga escala constitui-se em tendência vislumbrada nos diversos níveis da administração pública em todo o país, e tomada como prática por diferentes partidos políticos. As avaliações externas, enquanto via de regulação estatal da educação, consolidaram-se ao longo da década de 1990, tornando-se umas das mais efetivas políticas públicas para o campo da educação nos dias atuais. 


\begin{abstract}
Os diferentes e reiterados tipos de críticas aos chamados 'ineficientes sistemas burocráticos de governo' deram abertura e legitimidade à penetração crescente de uma nova lógica de administração derivada do setor privado. Essa nova lógica lentamente vai introduzindo formas, muitas vezes bastante sutis, de privatização, mas seu elemento-chave é a análise de desempenho de pessoas e de instituições. A garantia da implementação de políticas, que se estruturam e se desenvolvem com base na cultura do desempenho, é assegurada pela criação do Estado avaliador. (SANTOS, 2004, p. 1151).
\end{abstract}

Também não se pode desconsiderar que "[...] o ato de ensinar e a subjetividade do professor ambos sofrem profundas mudanças com o novo panopticismo da gestão (de qualidade e excelência) e as novas formas de controle empresarial (por meio do marketing e da concorrência)" (BALL, 2004, p. 1118). De modo que, no âmbito subjetivo, não somente se avalia, mas algo se constrói (ou se deturpa) mediante sucessivas avaliações padronizadas que fazem visíveis resultados, e avaliações que se fazem previsíveis em seus métodos.

\title{
O ranking educacional
}

A emergência de rankings pode ser tomada como um dos fenômenos que mais mobilizaram o campo educacional nos últimos anos. Tal questão, cujas dimensões são mundiais, configura uma tendência em diversos setores antes não submetidos a esse tipo de tratamento e análise: para além da Educação, também a Ciência, a Saúde, a Segurança Pública, dentre outros recortes da experiência social, são objetos de ranqueamentos que, além de fomentarem uma inoportuna competição, propõem juízos de valor sobre as condições, populações ou instituições avaliadas.

O termo ranking é comumente utilizado para descrever uma relação de posicionamento de um elemento frente aos demais, baseado em escores ou dados estatísticos. Trata-se de uma ferramenta de comparação amplamente utilizada, por exemplo, nos esportes e nos negócios, contextos em que a finalidade é, evidentemente, a competição. $\mathrm{O}$ ranqueamento expõe de modo acentuado os maiores e os menores, bem como os melhores e os piores, os "modelos" e os "párias".

Para além de sua forma pretensamente objetiva, é notável o poder de atração causado por tais recursos em uma dimensão propriamente subjetiva: a curiosidade que provocam e o poder de posicionamento que comportam, permitindo julgamentos rápidos e "fundamentados" sobre os mais diversos assuntos. Tal fundamentação viria, necessariamente, da suposta credibilidade do método utilizado e das agências avaliadoras, condições que imputariam aos dados obtidos o status de verdade. A título de clareza, cabe recorrer ao que pode ser considerado uma verdade dentro da perspectiva teórica a qual este trabalho se coaduna:

A verdade é deste mundo; ela é produzida nele graças a múltiplas coerções e nele produz efeitos regulamentados de poder. Cada sociedade tem seu regime de verdade, sua 'política geral' de verdade: isto é, os mecanismos e as instâncias que permitem distinguir os enunciados verdadeiros dos falsos, a maneira como se sanciona uns e outros; as técnicas e os procedimentos que são valorizados para 
a obtenção da verdade; o estatuto daqueles que têm o encargo de dizer o que funciona como verdadeiro. (FOUCAULT, 2002a, p.12).

Foucault propõe que é dentro de determinados jogos de verdade, de conjuntos de procedimentos, critérios de inclusão e exclusão, métodos, léxicos, etc., característicos de um contexto social em um dado momento histórico, que se viabiliza a possibilidade de enunciar o verdadeiro. O que seria um "efeito de verdade", ou o que funciona como verdadeiro? Primeiramente, pode-se considerar que a verdade pertence ao campo do discurso, é nele, e não na fiel apreensão dos fatos (por vezes impossível), que se institui o verdadeiro. E, segundo, não se pode pensar a verdade somente em sua dimensão representativa, mas também em suas implicações práticas: a verdade não está somente nos métodos utilizados, mas também nos efeitos que produz (FOUCAULT, 2002b; 2002c; 2005).

Para a compreensão dessas dimensões no ranqueamento educacional, podese recorrer a análise realizada por Andrade (2011) acerca dos fundamentos teóricometodológicos utilizados na construção dos rankings educacionais:

A educação pode ser entendida como um serviço que transforma insumos em produtos. Ela pode ser representada por uma função de produção, que mostra a relação existente entre esses insumos e produtos e, adicionalmente, corresponde também ao máximo de produção que pode ser alcançado dado os insumos utilizados.

$[\ldots]$

Uma versão alternativa deste modelo é comumente utilizada. Ao invés de usar o valor do produto num determinado ponto no tempo, o foco da análise é no valor adicionado. Ou seja, quanto que ocorreu de ganho no produto de um período para outro. ( ANDRADE, 2011, p. 326-327).

A escola, como acima exposto, é tomada como um lugar que produz ou que agrega valor, através da quantidade e qualidade de insumos aplicados, e na excelência dos processos desenvolvidos em seu interior. Tal afirmação explicita a raiz epistemológica do ranqueamento: são práticas amparadas em um saber derivado do campo econômico, e é neste mesmo campo que ele busca ser compreendido e gerar seus efeitos.

Andrade (2011) aponta alguns dos problemas metodológicos do ranqueamento, sendo o mais considerável o fato de que ele se sustenta em alguns pressupostos contestáveis. Como por exemplo, que a quantidade de insumos investidos do processo necessariamente aumenta a qualidade, o que pode não se confirmar na prática ou mesmo ser refutado por outro viés de avaliação. Bem como, constroem-se rankings através de coleta de dados subjetivos, os pareceres dos experts e do público amplo envolvido na instituição, o que revela um apanhado de pontos de vista que não necessariamente refletem qualidade - antes, são pesquisas de imagem e de opinião (caso bastante comum em ranqueamentos de instituições de ensino superior).

Embora o ranking educacional comporte estas fragilidades, ou seja, admita uma base metodológica suspeita ou francamente contestável, bem como seja uma prática que advém de um campo epistemológico alheio ao educacional, é inegável que 
ele vem causando "efeitos de verdade", conduzindo as ações dos sujeitos envolvidos. Andrade (2011) salienta que tais rankings, elaborados pelos governos, mas incluindo também aqueles organizados pelo setor privado (como por exemplo, o Guia do Estudante, da Editora Abril), geram consequências nas escolhas da futura "clientela" da instituição de ensino, bem como nos "consumidores finais" dos "produtos" da escola: o mercado de trabalho que emprega a mão-de-obra formada nas instituições avaliadas.

Reafirmando a função do ranqueamento, tem-se que:

O objetivo é fornecer informações sobre a qualidade das instituições para os diferentes stakeholders. Elas podem auxiliar pais/estudantes na escolha de onde estudar, empregadores na contratação de novos funcionários, governos nos seus programas voltados para a melhoria da qualidade da educação e o próprio MEC no seu trabalho de regulação do setor educacional. (ANDRADE, 2011, p. 324).

Também cabe pontuar que a ojeriza contemporânea aos grandes textos e às explicações detalhadas, observada no grande público, bem como a gestão governamental, baseada em dados estatísticos e indicadores numéricos, fazem do ranking um instrumento deveras poderoso na construção de uma leitura da realidade e de um posicionamento frente a ela. Os números, quando retirados de seu contexto de origem e ignorando os meios pelos quais foram obtidos, revestem-se de uma perigosa naturalidade. Como verdades, eles "aderem" à instituição as pessoas que a ela se vinculam. Neste processo, o número acaba retroalimentando a virtude ou a fraqueza da instituição avaliada, cooptando ou repelindo pessoas, direcionando ou desviando investimentos, reforçando ou denegrindo o apreço social da instituição avaliada, enfim, tendo um efeito econômico, político e moral considerável.

\section{Performatividade e os danos colaterais: consequências pe- dagógicas}

Como aponta Bauman (2008), grande parte dos esforços empreendidos por sujeitos e instituições na atualidade derivam de uma premente necessidade de "tornar-se consumível", o que pode ser traduzido, em outros termos, como ter prestígio, ter empregabilidade, ter um bom currículo, ter boas referências, enfim, tornar-se desejável ao olhar do outro dentro de um contexto povoado por relações "dinâmicas", entenda-se: por vínculos fugazes, à semelhança das práticas de consumo nas sociedades pós-industriais.

As universidades, as escolas, os alunos e os professores não deixaram de se posicionar frente a este panorama, empenhando-se individual e coletivamente, de modo tímido ou ostensivo, na busca por um olhar desejante do outro. De modo inequívoco, podemos reconhecer este "grande Outro" frente ao qual todos devem se moldar: o mercado.

$\mathrm{Na}$ esteira das premissas do mercado, a experiência educacional (mas não somente ela) passa a ser pautada pela inautenticidade, por uma cisão entre as convicções pessoais e a prática exigida e valorizada. Ball (2010) propõe que a performatividade e a responsabilização, reflexos de uma privatização (por vezes não consumada em 
termos econômicos, mas evidente em sua dimensão ideológica e funcional) que abarcou diversos setores da esfera pública, acarretam um processo de "fabricação" subjetiva, um exercício de auto-enquadramento nas metas e nos padrões validados pelas avaliações externas, que subverte a autoimagem profissional e o sentido do próprio trabalho. Afirma o autor que "[...] com efeito, nós nos criamos na medida da informação que construímos e transmitimos sobre nós mesmos. Nós nos articulamos dentro desses jogos representacionais de competição, intensificação e qualidade " (BALL, 2010, p. 38). Cabe considerar que,

Se os desempenhos visam à construção de uma cultura, a obtenção de orgulho e prestigio, por outro lado, as classificações e competições entre grupos, sem dúvida, geram sentimentos individuais (inveja, orgulho e vergonha, etc) que atingem e influenciam as esferas emocionais e racionais. Tais pressões por um bom desempenho individual para contribuir para a performatividade do grupo, passa a gerar um interesse focado apenas na produtividade e seus valores embutidos. (CALDERÓN, MATIAS \& LOURENÇO, 2013, p. 6-7).

A cultura da performatividade materializa-se em políticas meritocráticas, de valorização, remuneração e premiação por resultados, que estabelecem e formalizam a pressão por produtividade e concorrências intra e interinstitucionais. Formar alunos treinados como exímios respondedores de testes, em uma escola com dinâmicas pedagógicas típicas de cursos preparatórios para exames, passa a ser, embora um contrassenso em termos pedagógicos, algo legitimado como uma "boa prática educacional" através da verdade exposta pelas avaliações e rankings educacionais. Como propõe Santos (2004), "[...] os alunos terminam, desde os primeiros anos da educação fundamental, por ser treinados para obter bons resultados nos testes em vez de serem educados no sentido amplo deste termo" (p. 1153).

Neste sentido, reforça Ball (2010),

Existe a possibilidade de que o compromisso, o julgamento e a autenticidade dentro da prática sejam sacrificadas pela imagem e pela performance. Há uma potencial cisão entre o julgamento do próprio professor sobre, de um lado, o que significa uma boa prática e as necessidades dos estudantes e, de outro, o rigor da performance. (BALL, 2010 , p. 42, grifos do autor).

Outra tendência que pode ser observada é a padronização do ensino como reflexo direto da forma das avaliações externas, uma espécie de "aprisionamento curricular" em função das matrizes de referência dos testes. Qualquer princípio de liberdade na produção e opção por conteúdos, formas e temáticas a serem estudadas é sufocado pelo referencial teórico básico das grandes avaliações padronizadas, principalmente aquelas que obtêm seus dados através de testes de proficiência.

Ainda sobre esta forma de exame, Andrade (2011), com base em Hanushek e Woessmann, argumenta que existe "[...] forte evidência empírica de que a habilidade cognitiva de uma população [...] está fortemente relacionada com os ganhos dos indivíduos, a distribuição de renda e o crescimento econômico do país” (p. 334). Ou seja, em grande medida, condições extraescolares, fora do alcance da intervenção 
pedagógica, também determinam os resultados sobre a apropriação dos conteúdos disponibilizados pela educação formal.

Ravitch (2011), ao observar as consequências de reformas educacionais norte-americanas alicerçadas em pressupostos do mercado, empreendidas a partir da década de 1980, reporta que a testagem padronizada, quando utilizada como critério maior de validação de uma prática educacional, pode acarretar o empobrecimento do currículo e subverter os objetivos da educação, direcionando-os a conquista de índices numéricos e não uma formação integral. Esta conversão se dá frente à utilização dos indicadores de aproveitamento dos alunos como referencial para a responsabilização dos professores, e para que esses sejam, meritocraticamente, recompensados ou punidos. Tais para-efeitos das avaliações externas padronizadas são apresentados como fatos consumados em diversas experiências estadunidenses analisadas pela autora, apontando objetivamente para a precariedade de uma transposição dos moldes de gestão mercantis para a educação. Ravitch também atenta para o uso desses mecanismos de avaliação como forma de forçar a privatização da educação, vinculando, de modo simplista, os maus resultados à gestão pública das escolas, criando a relação, ideologicamente embasada, público=precário versus privado=eficiente.

Neste cenário, “[...] os valores e incentivos das políticas de mercado legitimam e dão impulso a certos compromissos e ações - empreendimento, competição, excelência - ao mesmo tempo que inibem e deslegitimam outros - justiça social, equidade, tolerância " (BALL, 2004, p. 1122). Tal movimento, cabe afirmar, configura um sério risco aos princípios que deveriam pautar a educação de um contexto que almeja uma forma de vida democrática e tolerante.

A cultura da performance sustentada pelas avaliações em larga escala há algum tempo vem batendo as portas da Educação Básica. Mesmo que com semblantes menos ostensivos do que aqueles já observados na Educação Superior, seus efeitos junto à mídia e ao grande público já se fazem sentir, servindo de argumento para qualificação ou desqualificação de redes de ensino, escolas e sujeitos envolvidos, bem como ditando parâmetros sobre os rumos da educação a serem seguidos. As releituras midiáticas, bem como a apropriação dessas pelo público, não podem ser tomadas como meros epifenômenos relativos à avaliação, pelo contrário, é nesta dimensão que se dão grande parte dos efeitos práticos de ordem política e econômica, bem como no campo das escolhas e dos julgamentos, frente aos números resultantes de avaliações padronizadas.

Tais avaliações fabricam verdades, mas essas não condizem necessariamente com aquilo que, em sentido amplo, poderia ser tomado como uma boa proposta educacional, ou um processo educacional bem conduzido. Antes, demonstram uma relação de intimidade para com as demandas deste "local de veridição" chamado mercado. Foucault (2008) propõe que o mercado, dentro do ideário liberal, proposto a partir do século XVIII, institui-se como um local de veridição, princípio revisitado e intensificado pelo neoliberalismo. Em uma concepção inicial, o mercado, quando submetido à mínima intervenção do Estado, deixaria agir a "natureza" do funcionamento econômico, fazendo emergir o preço "verdadeiro" daquilo que é objeto de troca, "[...] o 
mercado deve ser revelador de algo que é como uma verdade" (FOUCAULT, 2008, p. 44). As respostas do mercado irão, a partir daí, atestar a veracidade, definir o correto e o incorreto das práticas governamentais. A economia política não somente propôs teorias, mas também "[...] indicou onde o governo deveria buscar o princípio de verdade de sua própria prática governamental” (FOUCAULT, 2008, p. 45).

Por esta perspectiva, compreende-se a evidência dada a indicadores numéricos que atestam eficácia, eficiência e performance das instituições educacionais. Esses são critérios de validação e legitimação evidentemente mercadológicos, efetivamente são esses os parâmetros seguidos em tudo o que se faz no âmbito produtivo; e também pela submissão ao mercado, a boa educação será aquela que der conta de suas demandas, aquela que "bem formar para o mercado de trabalho", tomando como irrelevantes os demais aspectos que compõe uma experiência formativa satisfatória.

\section{Considerações finais}

Cabe pontuar que, para uma escola adentrar a "alta performance", ela deve ajustar-se a uma série de condições, que podem ser sintetizadas em um simples quesito: possuir um seleto grupo de alunos treinados para este fim. Como observa Andrade (2011), o ranking pode vir em benefício daquelas escolas "[...] com menor preocupação em recuperar os alunos com maiores dificuldades de aprendizado em detrimento daquelas com políticas mais inclusivas. O problema é que estas últimas podem ser as mais eficientes na produção do serviço educacional " (p. 341). Ou seja, a "qualidade" captada pelas avaliações pode ser representativa de um arranjo favorável, em termos de população atendida, condições sócio-econômicas da população, ou práticas pedagógicas alinhadas com um modo produtivista de conceber a educação, para não dizer, um efetivo treinamento para os testes.

Relativizar as constatações das avaliações padronizadas em larga escala, incluindo olhares críticos que considerem o contexto e a forma de obtenção dessas informações, é uma forma de minimizar os seus efeitos deletérios, como o ajustamento das práticas pedagógicas aos exames. Cabe ponderar que "estudar para responder a uma pergunta já dada”, em outros termos, tomar a avaliação como objetivo último da prática educativa, é render-se ao inegável fascínio dos números, desconsiderando a diversidade material e subjetiva que compõe o cenário escolar, bem como a necessidade real dos educandos, o que seria, em última análise, abdicar da função humanizante que cabe à educação.

\section{Referências}

ANDRADE, E. C. Rankings em educação: tipos, problemas, informações e mudanças. Estudos Econômicos, São Paulo, v. 41, n. 2, jun., 2011. Disponível em: <http://www.scielo.br/scielo. php?script=sci_arttext\&pid=S0101-41612011000200005\&lng=pt\&nrm=iso >. Acesso em: 21 jun. 2013.

BALL, S. J. Performatividade, privatização e o pós-Estado do Bem-Estar. Educação e sociedade, Campinas, v. 25, n. 89, dez., 2004. Disponível em: <http://www.scielo.br/scielo.php?scrip$\mathrm{t}=$ sci_arttext\&pid=S0101-73302004000400002\&lng=pt\&nrm=iso >. Acesso em: 10 jun. 2013. 
BALL, S. J. Performatividades e fabricações na economia educacional: rumo a uma sociedade performativa. Educação \& Realidade, n. 35, v. 2, p. 37-55, maio/ago., 2010. Disponível em: < http://seer.ufrgs.br/educacaoerealidade/article/view/15865/9445>. Acesso em: 10 mai. 2013.

BAUMAN, Z. Vida para consumo. Rio de Janeiro: Zahar, 2008.

CALDERÓN, A. I.; MATIAS, R. C.; LOURENÇO, H. S. Os rankings na educação superior: uma aproximação ao ranking Playboy das melhores faculdades do brasil. Anais... XXVI Simpósio Brasileiro de política e Administração da Educação - ANPAE. Políticas, planos e gestão da Educação: democratização e qualidade social. UFPE, Recife, 27 a 30 mai. 2013. CD-ROM, p. 1-16.

FOUCAULT, M. Microfísica do poder. 17. ed. São Paulo: Graal, 2002a.

. A verdade e as formas jurídicas. 3. ed. Rio de Janeiro: Nau, 2002b.

.A ordem do discurso. 8. ed. São Paulo: Loyola, 2002c.

. A arqueologia do saber. 7. ed. Rio de Janeiro: Forense Universitária, 2005.

Nascimento da biopolítica. São Paulo: Martins Fontes, 2008.

ICLE, G. Para apresentar a performance à Educação. Educação e Realidade. Maio/ago., 2010, n. 35(2), p. 11-22. Disponível em: <http://seer.ufrgs.br/educacaoerealidade/article/view /15861/9473>. Acesso em: 10 mai 2013.

LYOTARD, J. F. A condição pós-moderna. 6. ed. Rio de Janeiro: José Olympo, 2000.

RAVITCH, D. Vida e Morte do Grande Sistema Escolar Americano: Como os testes padronizados e o modelo de mercado ameaçam a educação. Porto Alegre: Sulina, 2011.

SANTOS, L. L. C. P. Formação de professores na cultura do desempenho. Educação e Sociedade, Campinas, v. 25, n. 89, dez. , 2004. Disponível em: <http://www.scielo.br/scielo.php?scrip$\mathrm{t}=$ sci_arttext\&pid=S0101-73302004000400004\&lng=en\&nrm=iso $>$. Acesso em: 21 jun. 2013.

* Doutorando em Educação pela Universidade de Passo Fundo, Passo Fundo, Rio Grande do Sul, Brasil.

** Professora doutora da Universidade de Passo Fundo, Passo Fundo, Rio Grande do Sul, Brasil.

\section{Correspondência}

Rosimar Serena Siqueira Esquinsani - Universidade de Passo Fundo, Faculdade de Educação. Campus I

- BR 285 - Km 171. Bairro São José, CEP: 99001-970 - Passo Fundo, Rio Grande do Sul - Brasil.

E-mail: jarbas@upf.br - rosimaresquinsani@upf.br

Recebido em 07 de maio de 2014

Aprovado em 11 de fevereiro de 2015 